\title{
Physiological Tests on Soybean Mutant Lines against Stem Rot Disease Athelia Rolfsii Curzi
}

\author{
Paisal Mizra Mulyadi ${ }^{1}$, Diana Sofia Hanafiah ${ }^{2}$, Revandy Iskandar Muda Damanik ${ }^{3}$, Irda Safni ${ }^{4}$, \\ Luthfi Azis Mahmud Siregar ${ }^{5}$ \\ \{pmanday.pm@gmail.com ${ }^{1 *}$, dedek.hanafiah@yahoo.co.id ${ }^{2}$, damanik_revandy@hotmail.com $^{3}$ \} \\ ${ }^{1,2,3}$ Agroecotechnology Departmen, Faculty of Agriculture, Universitas Sumatera Utara, Indonesia \\ *pmanday.pm@gmail.com
}

\begin{abstract}
Soybean plants are often attacked by soil fungi that cause the plants to become wilted and generally caused by Athelia rolfsii Curzi. The research aims to test the physiology of soybean mutant lines against the stem rot disease of Athelia rolfsii Curzi. The results of data analysis showed that the inoculation of fungi to soybean mutant lines increases the content of the enzyme SOD and POD's in each soybean genotypes. There are lines selected with the character resistant to stem rot $A$. rolfsii Curzi namely M100 A17 (18/5), M100 A25 (3/7), M200 A17 (18/5) and M200 A12 (6/5).
\end{abstract}

Keywords: soybean, mutant lines, Athelia rolfsii Curzi, SOD, POD

\section{Introduction}

The efforts that can be done in increasing genetic diversity and the improvement of varieties to obtain superior varieties can be made through the induction of genetic mutations. One way that can be done with physical mutagen. The physical mutagen is as ionizing radiation, one of them is gamma ray [1].

One of the technological innovations that can improve soybean productivity is the use of superior varieties. In the period from 1918 to 2015 there are 83 varieties of soybeans that have been removed and sought to be distributed to farmers. These superior varieties have a variety of potential character outcomes, harvest age, seed size, seed skin color, resistance to biotic/abiotic stress, and adaptation areas [2].

One of the common fungi is A.rolfsii Curzi often attack soy, green beans, and peanuts in the gardens scope of the crops research of legumes and tuber-Umbian (Iletri). The results of identification of diseases of the plants that are attacked wilt generally show the disease caused by A.rolfsii Curzi. A.rolfsii Curzi fungus survives in the soil or remnants of plants in the form of Hyfa or Sclerotia as microorganisms that are of facultative parasites. A.rolfsii Curzi is the cause of the stem rot at the soybean crop. The fungus will live as saprophytes when the host plant is not found. In humid conditions, this fungus is also infected with soybean branches and leaves that are near the ground. Such microorganisms have the ability of low saprophyte competition activity [3].

The damage can caused by A.rolfsii Curzi can trigger changes to physiological, such as membrane disorders, nutrient imbalance, impairs the ability to detoxify reactive oxygen species (ROS). The concentration of ROS formed for the value of the highest SOD activity shows the plant to recovery itself to overcome the hick against the stem rot disease. The high 
antioxidant enzyme activity shows the plant balancing the content of the ROS increased sharply. The increase in SOD becomes one of the plants to cope with the effects of the trigger. The high value of SOD signifies that the inexperienced plant has undergone a change in metabolic activity in the plant cells where photochemical reactions have been obstructions [4].

In previous research the character of high production and tolerant of stem rot. The results of the study showed that the strains planted there were the selected strains with high production characters and the stem rot resistant to the base of A.rolfsii Curzi on the soybean generation of soy plant M200A17 (13/6), M200A17 (18/5) and M300A6 (33/8) [5].

Based on the results of previous research authors interested in continuing research on the observation of the incidence of diseases as well as analysis of the enzyme superoxide Dismuatisi (SOD) and peroxide dismutation (POD).

\section{Research Method}

This research was conducted in October 2019 until December 2019 in the Pasar 1 Setia Budi Medan. The material used in this study is 9 lines of putative mutants, Anjasmoro varieties as the parent of lines mutant. Fertilizer used is Urea, SP-36 and $\mathrm{KCl}$ as the basic fertilization, top soil as a medium to grow, polybag size $40 \times 50 \mathrm{~cm}$ as a place of planting media, insecticide-active material Profenofos to control pests, compost, bamboo, water, labels, trichodermabiopesticide, pure Culture A.rolfsii Curzi, Media of Potato Dextrose (PDA), coarse corn milled, cotton, HD/PP plastics, alcohol 96\%, Aquades, spritus, Aluminium foil, Cling Wrap, gloves, masks, PVP (Polyvinyl pyrrolidone), EDTA (acid Ethenadiaminatetraacetate), methionine, NBT (Nitro Blue Tetrazolium), Riboflavin, calcium chloride $(\mathrm{CaCl} 2)$, phenol, 4Dimethylaminoantipyrine, MES (M-2-(N-Morpholino) ethanesulfonic Acid), HEPES (M N(2-and) ethanol 95\%, phosphoric acid, hydrochloric acid $(\mathrm{HCl})$, acetone $80 \%$, filter paper, liquid nitrogen and other supporting substances in this study.

The tools used in this research are tape measure, bamboo marker, polybag size $10 \mathrm{Kg}$, watering can, camera, and stationery, graduated cylinder, petri dish, Bunsen burner, matches, Scalpel, Inoculating loop, Laminar Air Flow (LAF), biochemical microscope, analytical scales, mortar and pestle, centrifuges, reaction tubes, micropipette, spectrophotometer UV/VIS, pH meter, oven, centrifuge Thermoscientifict (Sorval Legend Micro 17R), vortex Thermolyne (speed control type 37600 mixer) and other tools that support in this research.

Land preparation, measuring $9 \mathrm{~m} \times 10 \mathrm{~m}$, filling polybag, thinning, fertilizing and pest control, on 7 days after planting (HST) is done by leaving a plant. Plants are preserved, treated and fertilized. Fertilizer administered a week after planting. Pest control of plants using insecticide-activated Profenofos ( $2 \mathrm{~g} /$ Liter of water) is given from the age of 2 weeks. Pathogenic inoculation of A.rolfsii Curzi into soybean plants is done by sowing $15 \mathrm{~g}$ of A.rolfsii inoculants / plants around the base of soybean plants that have been aged for 2 weeks. Analysis of the superoxide enzyme dismutase (SOD) and peroxide dismutase (POD) conducted in the Tissue Culture Laboratory of the Faculty of Agriculture Universitas Sumatera Utara. The leaf samples used are healthy leaves in the infected plant A.rolfsii Curzi performed on 3 weeks after inoculation of pathogens.

This research design used Factorial Randomized Block Design with one factor. The planted soybean seed is the seeds obtained from the previous generation. There are 9 genotypes and 1 varieties of soy. The comparative plant is a varieties of Anjasmoro as a source of elders in general there are 9 groups of genotypes used in land i.e. M (100)-A-25 
(3/7), M (100)-A-25 (2/7), M (100)-A-25 (3/4), M (200)-A-17 (18/5), M (200)-A-12 (6/5), M (200)-A-11 (32/3), M (100)-A-17 (18/5), M (200)-A-17 (13/7), M (100)-A-6 (30/2).

\section{Results and Discussion}

The research data was collected for two months at the research location, namely in Pasar 1 Setia Budi, Medan Indonesia. The data collected is needed to be analyzed in this study. The results of the collection and analysis of research data are described as follows

Table 1. Occurrence of the disease at the observation interval I-VIII days after inoculation

\begin{tabular}{ccccccccc}
\hline \multirow{2}{*}{ Genotypes } & \multicolumn{7}{c}{ INTERVAL } \\
\cline { 2 - 9 } & I & II & III & 1 V & V & VI & VII & VIII \\
\hline M100A25(3/7) & $33,33 \%$ & $33,33 \%$ & $33,33 \%$ & $33,33 \%$ & $33,33 \%$ & $33,33 \%$ & $66,66 \%$ & $66,66 \%$ \\
M100A25(2/7) & $0 \%$ & $33,33 \%$ & $33,33 \%$ & $33,33 \%$ & $33,33 \%$ & $33,33 \%$ & $100 \%$ & $100 \%$ \\
M100A25(3/4) & $0 \%$ & $0 \%$ & $100 \%$ & $100 \%$ & $100 \%$ & $100 \%$ & $100 \%$ & $100 \%$ \\
M200A17(18/5) & $33,33 \%$ & $33,33 \%$ & $33,33 \%$ & $33,33 \%$ & $33,33 \%$ & $33,33 \%$ & $33,33 \%$ & $33,33 \%$ \\
M200A12(6/5) & $33,33 \%$ & $33,33 \%$ & $33,33 \%$ & $33,33 \%$ & $33,33 \%$ & $33,33 \%$ & $33,33 \%$ & $33,33 \%$ \\
M200A11(32/3) & $66,66 \%$ & $66,66 \%$ & $100 \%$ & $100 \%$ & $100 \%$ & $100 \%$ & $100 \%$ & $100 \%$ \\
M100A17(18/5) & $33,33 \%$ & $33,33 \%$ & $33,33 \%$ & $33,33 \%$ & $33,33 \%$ & $33,33 \%$ & $33,33 \%$ & $33,33 \%$ \\
M200A17(13/7) & $33,33 \%$ & $66,66 \%$ & $66,66 \%$ & $66,66 \%$ & $100 \%$ & $100 \%$ & $100 \%$ & $100 \%$ \\
M100A17(30/2) & $0 \%$ & $33,33 \%$ & $33,33 \%$ & $33,33 \%$ & $33,33 \%$ & $33,33 \%$ & $33,33 \%$ & $33,33 \%$ \\
ANJASMORO & $33,33 \%$ & $33,33 \%$ & $33,33 \%$ & $66,66 \%$ & $66,66 \%$ & $100 \%$ & $100 \%$ & $100 \%$ \\
\hline
\end{tabular}

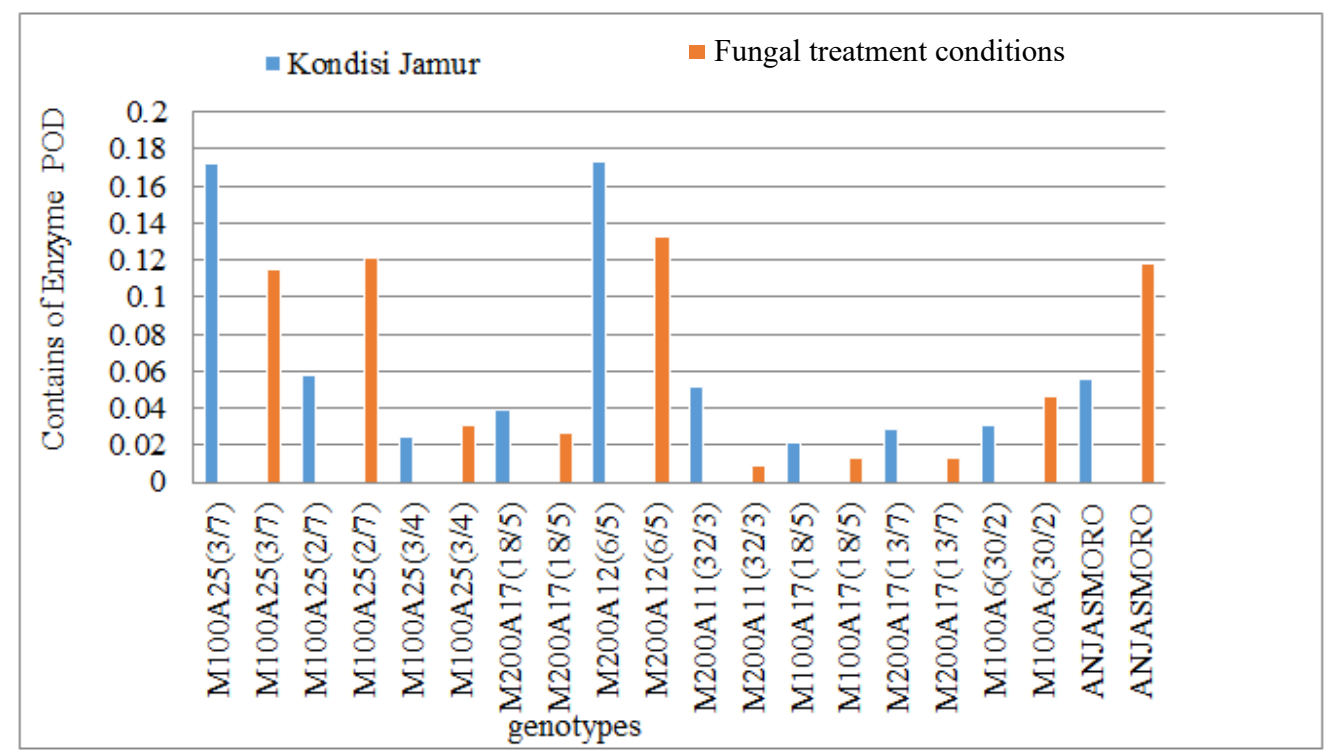

Fig 1. Results of analysis of the enzyme Peroxide Dismutase (POD) on some genotypes 


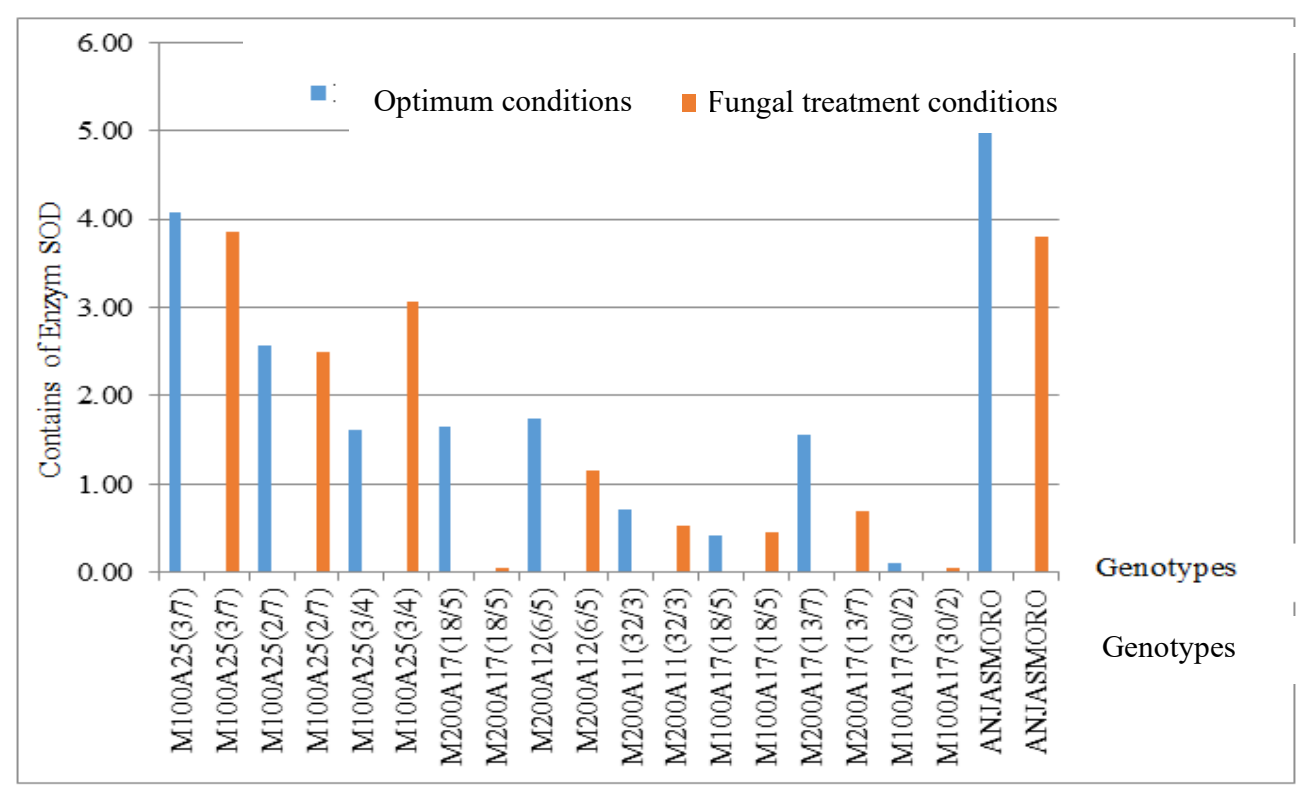

Fig 2. Analysis result of superoxide Dismutase (SOD) enzyme in several genotypes

\section{Discussion}

Results showed that disease infections in plants had occurred from the incidence of disease interval I ( 7 days after inoculation) to Interval VIII (28 days after inoculation). Based on visual observations made, the most disease attacks on genotypes M100A25 (3/7), M100A25 (3/4), M200A11 (32/3), M100A6 (30/2), and Anjasmoro by $100 \%$. The lowest disease attack was found in genotypes M200A17 (18/5), M200A12 (6/5), and M100A17 $(18 / 5)$, respectively, $33.33 \%$. The intensity of the stem rotten disease is attacking plants depending on genotypes and varieties of plants that are able to survive is that has a character resistant to the stem rotten disease. Starting from small to entering the generative phase which states that stem rot diseases attack since the vegetative phase and evolved to the generative phase so as to lower production. Infection of the disease shows the severity depending on varieties or genotypes [5].

Based on the analysis of parameters observed superoxide enzyme dismutation, the condition of the plant in a state of stress fungus SOD highest value is present in the Anjasmoro (5.164 units $/ \mathrm{mg}$ protein) and the lowest is at the lowest in Optimum condition M100A6 (30/2) ( 0.098 units/mg protein). The higher the value of SOD, it will hold the crop to a shallow. This is due to the enzyme SOD is an important component in the handling of Reactive oxygen Species (ROS) is done in chloroplasts and mitochondria. The value of the highest SOD activity indicates the plant to recovery itself to overcome the disaster that occurs in plants. The high antioxidant enzyme activity shows the plant balancing the content of the ROS increased sharply [4].

The results showed that some strains that had a higher pod content in the pathogenic condition were the administration of the stem rot rotten fungus compared to its control plant in 
genotypes M100A25 (3/7), M200A12 (6/5), M200A17 (18/5), M200A11 (32/3), M100A17 $(18 / 5)$, and M200A17 (13/7). This genotyping has a resistance to the stem rotten pathogenic disease. Peroxidase activity plays an important role in plant cell wall strengthening mechanisms (lignification) and the production of phenolic compounds. Reinforcement of cell wall plants can inhibit the initial infection process of pathogens because pathogens require nutrients from within the plant cells. In addition, the plant cell serves as the venue for mechanisms governing the activity of crop defense response to pathogenic attacks [6].

Interaction between SOD enzyme and POD relationship that is SOD is the first defense system in tackling the damage caused by ROS by catalyzed the $\mathrm{O}_{2}$ into hydrogen peroxide $\left(\mathrm{H}_{2} \mathrm{O}_{2}\right)$. Peroxide is an enzyme that plays a role in crop resistance to pathogenic attacks such as stem rot mold. The content levels of SOD and PODS affect crop defense against the stem of rotten fungus disease based on research in the find that genotypes that have resistance to stem rot are M200A17 (18/5), M200A17 (13/7), M200A11 (32/3), M200A12 (6/5) and M100A25 (3/7) states that Superoxide produced on the membrane surface thus can be trapped and converted immediately into $\mathrm{H}_{2} \mathrm{O}_{2}$. Peroxidase solves $\mathrm{H}_{2} \mathrm{O}_{2}$ into water when oxidizing a number of substrates. Thus peroxidase is an enzyme of oxidoreductase group which uses $\mathrm{H}_{2} \mathrm{O}_{2}$ as an electron acceptor to be catalyzed the various oxidative reactions occurring within the plant [7].

Based on the results of the incidence of disease obtained that there is genotyping the percentage of attacks on the base rotten disease and has a high content of SOD enzyme and enzyme POD so that the plant is more resistant to A.rolfsii Curzi at M200A17 (18/5) which percentage of the incidence of disease is $33.33 \%$ and SOD content is $4931.40 \mathrm{units} / \mathrm{mg}$, POD 0.12 units/mg, M6200A11 (6/5) percentage of the incidence of diseases ranging from $33.33 \%$ and SOD content is 1740.65 units/mg, POD of 0.17 units $/ \mathrm{mg}$. There are several genotypes that have a high content of SOD enzymes and POD enzymes but have a high incidence of disease also in genotypes M100A17 (18/5) percentage of disease incidence is $33.33 \%$ and SOD content is 422 units $/ \mathrm{mg}$, POD of 0.02 units $/ \mathrm{mg}$ and M100A25 (3/7) percentage of the incidence of its disease, ranging from $66.66 \%$ and SOD content of 4066.57 units $/ \mathrm{mg}$ than POD content of 0.17 units $/ \mathrm{mg}$ of research results showed agronomy character appearance on a medium inoculated fungus A.rolfsii Curzi lower than treatment without inoculation of A.rolfsii Curzi on population. Selections performed on the population of mutant lines produce selected individuals with a tolerance of stem-rotten disease ranging from 100Gy and the population of 200 Gy [8].

\section{Conclusions and suggestions}

There are lines selected with the character resistant to stem rot $A$. rolfsii Curzi namely M100 A17 (18/5), M100 A25 (3/7), M200 A17 (18/5) and M200 A12 (6/5). It is advisable to do planting soybean in field of production center in North Sumatera. 


\section{Acknowledgements}

The author wishes to thank Rector of the Universitas Sumatera Utara and the Ministry of Research, Technology and Higher Education, Republic of Indonesia who has supported and funded this research.

\section{References}

[1] Sudaryanto, T. and D. K. S. Swastika. Soybean economy in Indonesia. Socio-economic analysis and agricultural policy. Bogor. (2007).

[2] The Biogen Great Hall. A mutation technique for plant breeding. Agency for Agricultural Research and Development. (2014).

[3] Sumartini. Soil diseases (Sclerotiumrolfsii and RhizoctoniaSolani) in legumes and tubers and how to control them. Research Hall for legumes and tuber crops, Malang. Agricultural Research and Development Journal. (2011).

[4] Wibowo, F. The demonstration of morphology, physiology and biochemistry the results of a cross of F2 soybean plant (Glycine max (L.) Merr.) in the Cekaman of salinity. Repository USU. University of North Sumatera. Medan. (2010).

[5] Matondang R. M. Strain selection on soybean plant (Glycine max L. Merrill) generation M6 based on character high production and resistant foul disease of the root of the stem AtheliarolfsiiCurzi. Faculty of Agriculture. University of North Sumatera. (2018).

[6] Marwan, H. Scanning of banana crop resistance to blood disease (RalstoniasolanacearumPhylotype IV) using endophytic bacteria. (2014).

[7] Neubauer, C. and Schreiber, U. Photochemical and Non-Photochemical Quenching of Chlorophyll Fluorescence Induced by Hydrogen Peroxide. (1989).

[8] Rahmah, M. Hanafiah, S. D, Siregar, L.A. M, Safni, I. Selection individual on mutant genotype of soybean (Glycine Maxl. Merrill) in M5 generation based on resistance of stem rot disease Atheliarolfsii (Curzi). IOP Conference Series: Earth and Environmental Science. (2018). 